\title{
An Analysis of the Basic Clause Types of the Students' Syntactic Competence
}

\author{
Muhammad Basri D. ${ }^{*}$, Sitti Halijah ${ }^{2}$ \\ ${ }^{1}$ Department of English, Faculty of Letters, UMI Makassar, South Sulawesi, Indonesia \\ ${ }^{2}$ Department of English Education, Faculty of Letters, UMI Makassar, South Sulawesi, Indonesia
}

\begin{abstract}
The article was concerned with the results of a descriptive study about the basic clause types that the students had recognized in the objective test. The aims of the study were to know the students' syntactic competence in the case of the seven basic clause types and to describe their problems to make the distinctions between one type and the others. The research samples consisted of 80 persons. The data were analyzed by using a mean percentage. The research findings indicated that the six semester students got the fewest scores of SPOA (3.75\%) and SPOC (13.75\%); the fewer scores of SPOO (21.25\%) and SPO (22.50\%); and the few scores of SPA $(30.00 \%)$, SPC $(31.25 \%)$, and SP $(36.25 \%)$. The main problematic issue faced by the students was to distinguish the SPO type from SPC (26.25\%), meaning that the difference between object and complement had become the confusion for the students. It was recommended that these basic clause types be discussed in syntax class by giving more examples to the main problems faced by the students in order that they could differentiate among the clause types.
\end{abstract}

Keywords: Basic Clause Types, Syntactic Competence

\section{Introduction}

In this world there are about 6,000 languages spoken, and English has become the global language of the world. English has become the first largest language from a number of countries using it as an official language. Today it is still ranked first as the international language and the language of the global world ${ }^{[1]}$. English has become the third largest if it is seen from a number of native speakers, i.e. 341 million inhabitants, with at least 140 countries, after Mandarin Chinese with 874 million inhabitants of 16 countries, and Hindi (India) with 366 million inhabitants of 17 countries ${ }^{[2]}$.

The influence of global information that flows very rapidly makes the language very important to highlight the role of the social status and function, so that all of them can be applied well within the scope of both linguistic and non-linguistic matters. Besides, the matters of competence and performance are obviously crucial in learning a language ${ }^{[3]}$. The knowledge of linguistic structure is referred to as competence, whereas the realization of this knowledge in actual event is called performance ${ }^{[4]}$. In learning a language, both competence and performance should be achieved by the students.

The linguist sees a language as form, namely sounds or letters and their combinations into larger units, such as words, sentences, and so forth. This is the problem of syntax in a language form ${ }^{[5]}$. It is obvious that syntax is the one dealing with the way in which words are put together to express thoughts or ideas sensibly [6].

The example is that 'The dog frightened the child' is a sentence. At an intuitive level the dog, frightened and the child appear relevant constituents in a way that strings like frightened the or dog frightened do not. The word 'string' is supposed to be used as a neutral term to refer to any sequence of constituents. The words the dog or frightened the child or indeed the whole of sentence as strings without a commitment as their status as constituents or any identification of the type of constituents. Furthermore, again at an intuitive level the strings the dog and the child seem to be constituents of the same type ${ }^{[7] .}$

A study of syntax contains analyses. The well-known analyses are bracketed, immediate constituent, and tree diagram analyses. Each of these has a definite use to make the students understand for identifying and classifying the syntactic categories with their functions. The subject requires competence and performance and the linguistic knowledge and language skills. Therefore, to design a model for the instructional materials of the English syntax, we need to know all syntactic matters with these analyses. 
The areas of syntax cover the English phrases and clauses. A phrase is a word or a group of words that form a particular meaning grammatically. The phrase may identify a referent, indicate the action of, modify, or qualify grammatical elements in sentences ${ }^{[8]}$. Words are organized into phrases, groupings of words that are clumped as a unit and a sentence can be modeled as a set of phrases ${ }^{[9]}$. The previous study found that the phrase is significantly importance to analyze the distribution clause using machine translation ${ }^{[10]}$.

The English phrases have various divisions, i.e.: noun phrase (NP), verb phrase (VP), adjective phrase (Adj P), adverb phrase Adv P), and prepositional phrase (Prep P). The English NP is very important because this type can fill in four functions: subject, object, complement, and adjunct. A predicate function is filled in by a VP. The English clauses include independent or main clauses and dependent or subordinate clauses. This article focuses on discussing the independent or main clauses; they are seven basic clause types: (1) Subject Predicate, (2) Subject Predicate Adjunct, (3) Subject Predicate Complement, (4) Subject Predicate Object, (5) Subject Predicate Object Adjunct, (6) Subject Predicate Object Object, and (7) Subject Predicate Object Complement.

It is stated that the subject function is normally filled in by an NP; the predicate function is always filled in by a VP; the object function may be filled in by either an NP or a Prep P; the complement function may be filled in by either an NP or an Adj P; and the adjunct function is filled in by an Adv P, a Prep P, or an NP ${ }^{[11]}$.

The basic structure of clauses is simply composed of ' $\mathrm{S}+\mathrm{P}$ ' as constant elements, and what follows these elements depends on the kinds of clause types. These types are called main or independent clauses. The other clauses are called subordinate or dependent clauses; they are very complex. Therefore, the English phrases are required to be mastered immediately as the basic constituents in constructing any clause. For example, in a sentence (an independent clause) 'The Indonesian students should understand the English word classes' has a syntactic structure as an SPO (Subject, Predicate, and Object). The function of the phrase 'The Indonesian students' is a subject; the function of 'should understand' is a predicate; and that of 'the English word classes' is an object. These three functions are obligatory constituents in this clause. The meaning of a clause is not clear if one of these constituents is omitted.

It should be remarked that syntax establishes the coordinated system of form and meaning. Any thought in the language can be expressed in different forms. Sometimes two semantic descriptions in a sentence appear: real or concrete and idiomatic or figurative ${ }^{[12] .}$ In syntactic evidence, the sixth semester (level 3) students have got greater accurate performance than their inaccuracy $(54.97 \%>36.34 \%)$. Anyhow, there are still a number of non-productive features of syntactic evidence, i.e.: future tense, perfective aspect, simple past, past perfect, and present perfect voices, and interrogative of indicative and purpose of subjunctive moods. The implication of the above statements suggests that those students be trained intensively to acquire morphological and syntactic categories with their related features, so that they will be able to use these categories with their features in their interactive utterances ${ }^{[13]}$.

\section{Method and Materials}

The research problems were oriented to syntactic issues of the learning products. The population consisted of the sixth semester students of English department, Faculty of Letters, Indonesia Moslem University in Makassar. The samples consisted of 80 students. The research variables covered the students' competence of the seven basic clause types and the problematic issues shown in deciding the basic type of independent clause.

The research instrument that had been used to gather the data was a competence test. The test consisted of seven items in which the testees had to choose the numbers provided in brackets after each of the clause type. These items were included in the whole parts of the test. The time used for doing the whole parts of the test was 90 minutes. The results of test were classified as the quantitative and primary data. The rating score was ranged from 0 to 10 .

The above categories were concerned with the substances of the independent clauses, including the seven basic clause types: (1) Subject Predicate (SP), (2) Subject Predicate Adjunct (SPA), (3) Subject Predicate Complement (SPC), (4) Subject Predicate Object (SPO), (5) Subject Predicate Object Adjunct (SPOA), (6) Subject Predicate Object Object (SPOO), and (7) Subject Predicate Object Complement (SPOC). Based on the results of competence test, the correct and incorrect options were counted for being further computed in percentage rates. Finally, the results of calculations were tabulated, exposed, and interpreted. 


\section{Results and Discussion}

The findings specify the interpretations of the students' competence of the seven basic clause types and the problematic issues shown in deciding the basic type of independent clause by the sixth semester students of English department, Faculty of Letters, UMI Makassar. Table 1 below is concerned with the sixth semester students' competence of the basic clause types that had been recognized in the syntactic test. And, Table 2 refers to the problematic issues faced by the sixth semester students in making the distinction among the seven basic clause types.

Table 1. The students' competence of the seven basic clause types

\begin{tabular}{|l|l|l|r|r|r|}
\hline No & \multicolumn{1}{|c|}{ Types } & \multicolumn{1}{|c|}{ Examples } & Q & \multicolumn{1}{c|}{ Scores } & \multicolumn{1}{c|}{$\%$} \\
\hline 1 & SP & A few people cannot sleep. & 29 & 3.63 & 36.25 \\
2 & SPA & The book is on the table. & 24 & 3.00 & 30.00 \\
3 & SPC & They have been full. & 25 & 3.13 & 31.25 \\
4 & SPO & The Indonesian students should understand the English & 18 & 2.25 & 22.50 \\
& & word classes. & & \\
5 & SPOA & The English language has a foreign status in Indonesia. & 3 & 0.38 & 3.75 \\
6 & SPOO & My uncle will give Mary a dictionary. & 17 & 2.13 & 21.25 \\
7 & SPOC & I imagined your aunt much fatter. & 11 & 1.38 & 13.75 \\
\hline \multicolumn{2}{|l|}{ Total } & 127 & 15.90 & 158.75 \\
\hline \multicolumn{2}{|l|}{ Mean } & 18.14 & 2.27 & 22.68 \\
\hline
\end{tabular}

Table 1 indicates the results of a descriptive study about the basic clause types that the sixth semester students have recognized in the objective test. The results of analysis can be classified into three rates: the most problematic issue (the fewest percentage of syntactic competence), the more problematic issue (the fewer percentage of syntactic competence), and the problematic issue (the few percentage of syntactic competence).

It has been shown the table above that the SPOA type with the example 'The English language has a foreign status in Indonesia' has been recognized as the most problematic issue in which their competence is $3.75 \%$. It is the fewest percentage of syntactic competence for the SPOA type. The example of this type can be analyzed by using brackets as follows: The English language (S:NP) has (P:VP) a foreign status (O:NP) in Indonesia (A:Prep P). Thus, this is one of the types (SPOA) that has been recognized as the most problematic issue. Another one is the SPOC type with the example 'I imagined your aunt much fatter' which is also the most problematic issues being recognized in the syntactic competence. Its percentage rate is $13.75 \%$. The analysis of this clause type is as follows: I (S:NP) imagined (P:VP) your aunt (O:NP) much fatter (C:Adj P).

The next problematic issue has been classified as the more problematic issue (the fewer percentage of syntactic competence). This issue contains two types: SPOO, and SPO. The problematic issue is the SPOO clause type. The example of this type with its bracketed analysis is 'My uncle (S:NP) will give (P:VP) Mary (O:NP) a dictionary (O:NP)'. This type is called the di-transitive clause one ${ }^{[11]}$. It has two objects which are distinguishable in terms of a direct object (a dictionary) and an indirect object (Mary). Another classification of the fewer percentage of syntactic competence is SPO $(22.50 \%)$; e.g. The Indonesian students should understand the English word classes. The functions and categories of this type are as follows: The Indonesian students (S:NP) should understand (P:VP) the English word classes (O:NP).

The last problematic issue has been classified as the problematic issue (the few percentage of syntactic competence). This issue contains three types with their own percentage rates: SPA $(30.00 \%)$, SPC (31.25\%), and SP (36.25\%). The example of SPA type in the table above is 'The book is on the table'. The syntactic analysis of this clause type is as follows: The book (S:NP) is (P:VP) on the table (A:Prep P). The next problematic issue in this classification is the SPC type. From the table above, the analysis of the example can be done as follows: They (S:NP) have been (P:VP) full (C:Adj P). And, the last case is the SP clause type. The bracketed analysis of the given example is as follows: A few people (S:NP) cannot sleep $(\mathrm{P}: \mathrm{VP})$. The clause has been classified as an intransitive clause one in which the subject does not affect anybody or anything else ${ }^{[1]}$.

Based on the above exposition, it can be concluded that the rating score of the sixth semester students' competence of the seven basic clause types is not so great as it has been expected. The mean score is 2.27 $(22.68 \%)$. Therefore, it is recommended that the seven basic clause types be discussed in the classroom by 
giving more examples to the principally problematic issue and applying the syntactic analyses to identify each constituent in any construction, so that the students are able to differentiate among the clause types.

Table $2 \mathrm{a}$ and Table $2 \mathrm{~b}$ below show the quantity and percentage rates of problematic issues concerning the seven basic clause types that the sixth semester students have experienced in their own objective test, respectively.

Table 2a. The quantity of problematic issues of the seven basic clause types

\begin{tabular}{|l|l|l|l|r|r|r|r|r|r|r|}
\hline No & Types & Key & \multicolumn{1}{l|}{$\begin{array}{l}\text { Correct } \\
\text { Options (Q) }\end{array}$} & \multicolumn{9}{|c|}{ Incorrect Options (Q) } \\
\cline { 5 - 10 } & & & $(\mathrm{K})$ & 1 & 2 & 3 & 4 & 5 & 6 & 7 \\
\hline 1 & SP & 1 & 29 & $\mathrm{~K}$ & 31 & 10 & 7 & 1 & 1 & 1 \\
2 & SPA & 2 & 24 & 21 & $\mathrm{~K}$ & 22 & 11 & 0 & 1 & 1 \\
3 & SPC & 3 & 25 & 17 & 25 & $\mathrm{~K}$ & 7 & 4 & 2 & 0 \\
4 & SPO & 4 & 18 & 0 & 12 & 21 & $\mathrm{~K}$ & 4 & 14 & 11 \\
5 & SPOA & 5 & 3 & 0 & 14 & 6 & 8 & $\mathrm{~K}$ & 5 & 44 \\
6 & SPOO & 6 & 17 & 1 & 9 & 8 & 23 & 6 & $\mathrm{~K}$ & 16 \\
7 & SPOC & 7 & 11 & 5 & 8 & 17 & 4 & 23 & 12 & $\mathrm{~K}$ \\
\hline
\end{tabular}

Table $2 \mathrm{~b}$. The percentage of problematic issues of the seven basic clause types

\begin{tabular}{|c|c|c|c|c|c|c|c|c|c|c|}
\hline \multirow[t]{2}{*}{ No } & \multirow[t]{2}{*}{ Types } & \multirow{2}{*}{$\begin{array}{l}\text { Key } \\
\text { (K) }\end{array}$} & \multirow{2}{*}{$\begin{array}{l}\text { Correct } \\
\text { Options } \\
(\%)\end{array}$} & \multicolumn{7}{|c|}{ Incorrect Options (\%) } \\
\hline & & & & 1 & 2 & 3 & 4 & 5 & 6 & 7 \\
\hline 1 & SP & 1 & 36.25 & $\mathrm{~K}$ & 38.75 & 12.50 & 8.75 & 0.13 & 0.13 & 0.13 \\
\hline 2 & SPA & 2 & 30.00 & 26.25 & $\mathrm{~K}$ & 27.50 & 13.75 & 0.00 & 0.13 & 0.13 \\
\hline 3 & SPC & 3 & 31.25 & 21.25 & 31.25 & $\mathrm{~K}$ & 8.75 & 5.00 & 2.25 & 0.00 \\
\hline 4 & SPO & 4 & 22.50 & 0.00 & 15.00 & 26.25 & $\mathrm{~K}$ & 5.00 & 17.50 & 13.75 \\
\hline 5 & SPOA & 5 & 3.75 & 0.00 & 16.25 & 7.50 & 10.00 & $\mathrm{~K}$ & 6.25 & 55.00 \\
\hline 6 & SPOO & 6 & 21.25 & 0.13 & 11.25 & 10.00 & 26.25 & 7.50 & $\mathrm{~K}$ & 18.75 \\
\hline 7 & SPOC & 7 & 13.75 & 6.25 & 10.00 & 21.25 & 5.00 & 28.75 & 15.00 & $\mathrm{~K}$ \\
\hline
\end{tabular}

The results indicate that the students get the problems to make a distinction between SP and SPA. The students decide SPA (38.75\%) and SPC (12.50\%) as the incorrect options for SP. In deciding the SPA type, two incorrect options have greater percentages; they are SP $(26.25 \%)$ and SPC $(27.50 \%)$. Besides, the students are also confused of deciding the SPC type because of these two types: SP and SPA. They get a problem to distinguish the SPC type from the SP type (21.25\%) and the SPA type (31.25\%). This is the main problem of SPO is to distinguish this type from SPC $(26.25 \%)$, meaning that the difference between object and complement becomes the confusion for the students.

The following problematic issues to be discussed in the above tables are SPOA, SPOO, and SPOC types. The SPOA type is recognized as the SPOC type (55.00\%). This recognition means that they still get problem to differentiate between the function of adjunct and that of complement. Then, in recognizing the SPOO type, there are 23 students who choose SPO (26.25\%) and 16 students who choose SPOC (18.75\%). It means that the students need to know the distinction between the mono-transitive clause type and the ditransitive clause one. Besides, they also need to know the distinction between object and complement. The last problematic issue is that the students fail to gain the greater correct option of SPOC clause type $(13.75 \%)$ because they choose the SPOA type $(28.75 \%)$ and the SPC type $(21.25 \%)$. The two percentages of incorrect options are greater than the correct option of SPOC $(28.75 \%$ and $21.25 \%>13.75 \%)$.

The above two tables expose the reasons to make the students fail to achieve great quantity or percentage of syntactic competence in terms of the basic clause types. The choices of incorrect options are greater than the correct ones as the keys. The problem such as this requires the ways to get solutions for the sake of improvement of the students' syntactic competence. Thus, one of the ways to do so is to design a model for the instructional materials of the English syntax.

\section{Conclusion}

The article analyses the students' syntactic competence for the seven basic clause types and the problematic issues toward this competence. Dealing with syntax at the level of basic clause types, one gets to discover the skills of both language usage and use. We are sure that if the students master these seven clause types, they will be able to identify the phrase categories with their own functions. Anyhow, they still fail to gain 
greater syntactic competence for the seven basic clause types (22.68\%). The principal problem toward this competence is related to the recognition of SPOA $(3.75 \%)$ and SPOC $(13.75 \%)$. This case is affected by the problem to distinguish it from the SPOC clause type $(55.00 \%)$. The other two types which become the fewer competences for them are SPOO $(21.25 \%)$ and SPO $(22.50 \%)$. The problematic issues are related to their recognition of making the difference between the mono-transitive clause type and the di-transitive clause one and also related to their recognition of making the difference between the object and complement functions. Thus, the students are suggested that they study the functions of phrase categories with more examples and practice to use the syntactic analyses for identifying each constituent in various constructions.

\section{Acknowledgements}

We are indebted to Directoriate General of Higher Education, Ministry of Research and Technology, Indonesia for a grant provision of our research, so that the opportunity to write the article is possible.

\section{References}

1. D. Crystal. A World Language in the Encyclopedia of Language. Cambridge: Cambridge University Press. (1997)

2. D. O'Neil. Language Contact. Wikipedia, the free encyclopedia, the Wikimedia Foundation, Inc. (2010)

3. M. Basri, D., A. T. Ampa, and Junaid. Syntactic Errors in Descriptive Paragraphs by Native IndonesianSpeaking Students of English. IJL. 5 (5): 125-137. DOI: 10.5296/ijl.v5i5.4455. (2013)

4. R. Titone and M. Danesi. Applied Psycholinguistics. Toronto: University of Toronto Press. (1985)

5. R. T. Bell. An Introduction to Applied Linguistics: Approaches and Methods in Language Teaching. London: B.T. Batsford Ltd. (1987)

6. N. Harrison. Successful Writing. Peter Francis Publishers, Great Britain. (1987)

7. E. K. Brown. and J. E. Miller. Syntax: A Linguistic Introduction to Sentence Structure. London: Hutchinson. (1986)

8. Ravindra. Morphological Analysis of Verb Phrase in English Teaching. RJELAL. 4 (3): 558-564. (2016)

9. R. Prasad and M. P. Sebastian. A Survey of Phrase Structure Learning Methods for Text Classification. IJNLC. 3 (2): 33-46. DOI: 10.5121/ijnlc.2014.3203. (2014)

10. P. Phopiphat and R. Kongakchandra. The Recognition System of Sentential Noun Phrase Structure Using Conditional Random Field Model. IJAIA. 6 (4): 53-62. DOI: 10.5121/ijaia.2015.6405. (2015)

11. H. Jackson. Analyzing English: An Introduction to Descriptive Linguistics. Pergamon, Oxford. (1985)

12. G. I. Yusifova. Syntactic Features of English Idioms. IJEL. 3 (3): 133-138. DOI:10.5539/ijel.v3n3p133. (2013)

13. M. Basri, D. An Ecological Perspective on the Uses of the English Verbs in Interactions: A study at the English department of Faculty of Letters UMI Makassar. A Research Report (June 2005) A research report. Makassar: Faculty of Letters UMI. (2005) 